\title{
Introduction to A Research Agenda for Evaluation: inspirational themes
}

\section{Peter Dahler-Larsen}

What is evaluation? The question is simple, the answer complicated. We can begin by distinguishing between evaluation as a logical process, evaluation as a semi-professional field, evaluation as socio-political practices, and evaluation research.

Prominent attempts at defining evaluation as a logical process include Michael Scriven's:

The process of determining the merit, worth or value of something, or the product of that process ... The evaluation process normally involves some identification of relevant standards of merit, worth, or value [that are] explicated and justified; some investigation of the performance of the evaluands on these standards; and some integration or synthesis of the results to achieve an overall evaluation or a set of associated evaluations. (Scriven, 1991, p. 139)

Scriven's definition is interesting, since the object of evaluation is totally abstract; it is merely "something." This abstraction makes it possible to talk about all evaluation objects as "evaluands."

Scriven was instrumental in the liberation of evaluation as a logical process from any particular object, such as hotels, teaching, or social work. He searches for the logical common denominator across all those areas of life and all those practices, where evaluation has traditionally been an integrated part of those practices. Instead, his definition epitomizes a situation where evaluation can travel across time and space, making itself relevant for "something," if not "anything."

At the same time, he also abstracts evaluation from concrete human beings and socio-historical specificities, and his definition is so pure and clean that it 
does not even include consequences and the use of evaluation. In that sense, it is socio-historically empty. Human beings have presumably been evaluating things at least since they tried to use different kinds of stones for different kinds of tools. But that does not explain why, at a certain point in time, someone like Scriven decides to write up a formal definition. It is an attempt at defining evaluation as a logical process, but the attempt is unaware of its socio-historical underpinnings. And it does not open discussion of the massive wave of evaluation so characteristic of our contemporary society.

Next, let's say that someone wants to "go into the field of evaluation." They will then encounter courses on evaluation, evaluation conferences, evaluation journals, books, guidelines, and associations for evaluators such as the American Evaluation Association and the European Evaluation Society. In other words, they will encounter material embodiments of ideas, definitions, and models of evaluation. They will learn about data collection methods and good practices in evaluation.

They will also encounter attempts to structure what evaluation means and how it should be conducted. They may well encounter Scriven's definition along the way, but they will also meet a lot of other ideas about evaluation. Some of the key terms will be evaluands, but also values, methods, and forms of use of evaluation. These are the grand terms that people in the field often discuss, even if they use different evaluation models and have different ideas about evaluation and its purposes (Chelimsky, 2006; Shadish, Cook, \& Leviton, 1991). In the field of evaluation, you will also encounter plenty of terms and devices that help you handle specific situations: "terms of reference," "evaluability assessment," "commissioners," "stakeholders," "evaluation questions," "participation," "indicators," and many others.

But there are still some common denominators, such as ideals of clarity. The evaluator should be honest and competent and introduce the right tools. And above all, evaluation serves purposes such as accountability, learning, enlightenment, and public information (Chelimsky, 2006). Evaluation itself has to do with the imposition of a particular order on reflexive processes and the results of these processes. That is why most definitions (except Scriven's) include some component regarding the larger purposes of evaluation and its use.

In this sense, evaluation as a field, in all its diversity, shares some common and underlying ideas extending beyond evaluation as a mere logical process. And there is one overarching belief that unites all: Evaluation should be promoted, since it serves one or several of these good purposes. 
The evaluation field embodies ideals and imaginaries characteristic of the socio-political time and space in which the evaluation field has been formed (Dahler-Larsen, 2012). Evaluation transports modernity and rationality.

Let us now turn to evaluation as a socio-political practice. In recent years, we have seen a booming industry of audits, accreditation, benchmarking, performance indicators, tests, rankings, etc. Regardless of whether these practices travel under the official term "evaluation" or not, these varying activities are organized by a multitude of actors and redefine how social, professional, and political practices are understood at the local, national, and global levels. New "calculative spaces" are established (Grek, 2009; Grek et al., 2009).

These processes would be impossible without evaluation machineries, networks, infrastructure, and expertise. In interorganizational networks, demands for evaluative information and the delivery of this information are exchanged across time and place. As a corollary, the consequences of evaluation are spread over long distances in nonlinear ways. Evaluative information helps restructure practices such as teaching, research, health care, and social work.

A number of interesting sociological features characterize this development. The evaluator as a personified role is becoming less visible and replaced by an evaluative function embedded in large organizations, "quality departments," and "evaluation centers" (Raimondo, 2018). Evaluation is becoming an institutionalized, routine-based, and ongoing activity rather than a stand-alone process. At the same time that evaluation is becoming a more semi-autonomous process segregated into special institutional arrangements, it also provides a form of looking at the world where evaluation is seen as a particularly important and distinct part of social life rather than an aspect of life that is tacitly embedded in everything we do as human beings.

Its consequences are widespread through metrics, reporting mechanisms, interorganizational networks, and digital communication. Evaluation as a social practice has in practice expanded much beyond the somewhat artificial boundaries of the "field" of evaluation. The consequences of evaluation as a social practice are widespread, nonlinear, complex, contested, and not reducible to official purposes.

Evaluation as a set of socio-political practices has fundamentally "run away" from the preconceptions of evaluation that are taken for granted in the official field of evaluation. Evaluation is much more depersonalized, much more widespread, much more invasive, and much less understood than what we would think if we believed official evaluation self-understandings. Evaluation 
as a social practice is far more than what the (semi-)profession of evaluation acknowledges.

Evaluation has escaped from evaluation in more than one sense. Evaluation as an institutionalized practice is becoming such a normal practice that it has become difficult to raise skeptical questions about it. In some situations, evaluation is in demand not because it provides new knowledge but because it is seen as the obviously right thing to do. For example, parents are provided with evaluative data about their children in school not because they become better parents or more informed decision makers, but simply because they have a right to insight into such data. The evaluation society has become the normal state of affairs; normal in the sense of taken for granted, no longer requiring careful consideration of pros and cons.

As evaluation is becoming more widespread and institutionalized, however, it reveals costs, weaknesses, and side-effects that were not manifest and visible when evaluation was a new and promising ad hoc activity.

People with lengthy experience with evaluation are beginning to question unfettered enthusiasm about evaluation, including Schwandt, Power, Mathison, Leeuw, Dahler-Larsen, and others. The skeptical turn in evaluation is not only inspired by philosophical worries about the assumptions on which evaluation builds as a modernist and rationalist enterprise (Schwandt, 2002). Perhaps it is because evaluation as a social practice has now become so institutionalized and existed for so long that some of its costs and side-effects are now becoming so visible that it is becoming difficult to ignore them. Thus: a skeptical turn in evaluation is not only needed but also on the way.

Let us therefore consider and reconsider the position of evaluation research in this situation. This term originally meant applied social research looking at contemporary policy problems (Rossi \& Freeman, 1985). Increasingly, however, evaluation research also means research on evaluation. For evaluation to take such a critical, research-based look at itself (i.e. for social science to reconsider the practical ramifications of its own engagement in practice), reflexivity is needed.

The purpose of this book is to offer a fresh perspective on a new research agenda for evaluation, while taking complications and reflexivities onboard. We begin this project by asking questions. 


\section{Questions}

Questions about the new social configurations of evaluation

Evaluation is becoming "organizationalized" and institutionalized. It takes place in networks and evaluation machineries that extend in time and space. How can we understand these networks and machineries more specifically? What is the political economy of evaluation? What are the governance structures that regulate evaluation machineries? Given the many types of actors involved and the long chains of interaction through which they operate, how sensitive are these evaluation systems to feedback about their operations and the consequences of their operations? Is it a paradox that while some of these evaluation machineries are strongly undergirded by money, power, and expertise, they are also often under revision and change?

\section{Questions about involvement and participation}

Some professionals seek influence on the design of evaluation systems, but not everybody is in a position to do so. What are the conditions under which people under evaluation participate in the design, operation, and use of evaluation systems?

In complex systems, where it is not always possible to predict the next version of the system and its consequences, what are the ambiguities related to participation in the construction and operation of evaluation systems?

To what extent is evaluation improving governance, and to what extent is it sustaining existing inequalities - possibly introducing new ones related to evaluation expertise and evaluation literacy? For example, are evaluators in the global South too often relegated to a position where they merely serve as local liaisons and data collectors for international organizations? Can these roles be changed?

\section{Questions about evaluation data}

Data collected under the protection of experts sometimes remain hidden from the public eye, for example in international educational assessments.

What is known about the specificities and micropolitics influencing how data are collected? Are evaluative data as sensitive to these contextual phenomena as all other kinds of data, or more (Becker, 2017)? 
Is there a need to revise the very notion of data? Will digitally collected information and "big data" transform the very notion of data?

Is it increasingly accepted that data that are otherwise seen as having "low validity" (e.g. user assessments of hotels or reviews of films) suddenly become trustworthy, if only data is "big" and enough data are provided on the internet so that they can be used for "orientation" (Esposito \& Stark, 2019)? Will we have to fundamentally revise our notions of the relation between the validity of data and performativity of data?

\section{Questions about the consequences of evaluation}

"Use" is possibly the most worn-out aspect of conventional understandings of evaluation. The very notion of use suggests something instrumental in how people engage with evaluation. Paradoxically, at the same time, the notion of "use" has exploded into an ever growing set of forms of use (Behn, 2003; Mark \& Henry, 2003).

Alternatives to the notion of use have therefore been developed (Kirkhart, 2000). Constitutive effects has also been suggested as a term that captures the many ways in which practices are shaped in the image of evaluation systems (Dahler-Larsen, 2013).

Under some conditions, the restructuring effects upon managerial practices, educational practices, and the like are considerable (Espeland \& Sauder, 2007), but these effects do not occur automatically (Butler, 2010). Under which conditions do evaluation systems have such constitutive effects? Do the format and structure of evaluation data (e.g. rankings) play a particular role?

Under what conditions do intermediaries, middle managers, and brokers multiply and enhance the effects of evaluation systems (Dahler-Larsen, forthcoming)?

If the consequences of evaluation systems do not hinge on normative acceptance, and if people such as researchers are likely to use data from systems that they would otherwise criticize, the effects of such systems are conditioned on being implicated in these systems in ways that, until now, have been poorly understood. Implication seems to reach well beyond classical positions of being "for" or "against." Implication is also more than conventional "participation"; it means that someone is inscribed and enrolled long before and long after formal invitations to "participate." Implication may be one of the keys to understanding the widespread character of constitutive effects. 
What kinds of feedback about constitutive effects will be understood and received by the people in a position to influence evaluation systems?

\section{Questions about concepts and perspectives}

Many evaluation systems are already structured in complex ways. Some of the existing concepts that are used as elementary building blocks in thinking about evaluation represent simple typified viewpoints that may be out of sync with present complexities. They run the risk of becoming zombie concepts.

For example, in a time when many organizations structure themselves so that they become auditable and evaluable (Power, 1997), and internal evaluators spend much of their time serving external demands (Mathison, 1991), the classical distinction between internal and external evaluation may become blurred and lose analytical power.

An important mechanism for the construction of effects is the anticipation of effects. Given the complexities of constitutive effects and the dislocation in time of such effects, a classical distinction between "formative" and "summative" use may also become increasingly obsolete.

In a similar vein, references are often made to the "unintended consequences" of evaluation without careful attention to whose intentions count at what time and why those people's intentions deserve to be used as a benchmark against which to assess the consequences of evaluation systems.

Terms describing the involvement of people in evaluations may also turn out to have been far too simple. Does a "learning process," for example, not involve controversy, pain, and existential turmoil (Klouzal, Shayne, \& Foran, 2003)? When people are "gaming" the evaluation system, it sounds like they are cynically using it for selfish purposes. But professionals such as doctors and nurses must sometimes tweak evaluation systems slightly to make certain courses of action for the treatment of their patients possible (Kerpershoek, Groenleer, \& de Bruijn, 2016). How useful is "gaming," then, as an analytical term?

It is time to reconsider how many of the conventional conceptual building blocks in evaluation carry unreflected normative loadings with them. Just like science has been found to be not only a provider of "clean" and objective knowledge but instead a carrier of myths, ideas, assumptions, and tacit views of the world (Feyerabend, 2010; Law, 2004; Morin, 1990; Wynne, 1996), evaluation also transports a similar baggage that remains hidden from view, even if it takes place under the official flag of "transparency." In fact, the notion of 
a transparent society is itself a myth. Not all values are transparent, not even in evaluation. Instead, evaluation is based on pre-evaluative values (values not questioned openly in each and every evaluation).

In concrete and practical ways, then, what is the baggage inherent in the conventional concepts and perspectives normally used by evaluators (Podems, 2018)?

\section{Questions about new practices}

We can imagine the world taken over by aliens, but we cannot imagine a world without evaluation. It's not going away. Perhaps we can imagine new practices, more reflexive forms of institutionalization, and forms of engagement that better recognize the multiplicities of values, the complications of practices, and the ambiguities of interpretation. This must be done, however, without assuming that being more explicit and including more values in the equation will make things easier or make evaluative problems go away.

Would it be a way forward to be cooler about evaluation, to not promise endless development, learning, and accountability, and to recognize more clearly that all evaluation is contingent, and all consequences of evaluation are human constructions?

\section{Questions about evaluation and democracy}

All forms of evaluation establish some distinction between something that is under evaluation, which is debatable, questionable, contingent, up for potential change, versus something that is slightly less questionable, such as the existing terms of reference, some expertise, some methodological rules, some starting points. If the latter is debated endlessly, the framework for evaluation will not hold, and evaluation cannot do its job.

Clearly, many different standpoints can be taken, and many forms of promises can be made to solidify any such framework. For example, if you claim to find an impact of an intervention, you must build on a concept of causality. If you want a deliberative form of evaluation, it builds on some acceptance of rules regarding who is entitled to participate, how the deliberative process is designed, and the rules regarding the kinds of statements that are accepted within the given deliberative process. 
All forms of evaluation depend on some starting point; some distinction between what is questionable and what is less questionable, what is contestable now and what is not.

In democracies, of course, everything can be debated. But if an evaluation is a debate and only a debate, it is not an evaluation.

So under what circumstances is it acceptable, within a democracy, to establish, in a given evaluation situation and only as long as the evaluation is in operation, a distinction between what is more contestable versus less contestable in the evaluation process at hand?

How can that question be handled? The question of democratically establishing the necessary contestability differential for evaluation to function, without freezing evaluation machineries into institutional apparatuses that are difficult to change?

What would the institutional solution be to the question of how to establish contestability differentials in evaluation in democratic ways?

Can new publics emerge as responses to evaluation systems and their consequences - not as "structures," but as sources of "common concern" (Dewey, 1946)? What is the potential of activist approaches to statistics (Bruno, Didier, \& Vitale, 2014)? Can evaluation systems learn to be more sensitive to feedback?

\section{The chapters}

Each of the chapters in this book cultivates its own perspective on these and related questions in a manner that reveals the diverse standpoints, interests, and experiences of the authors. I invite the reader to appreciate not only the tone and voice of each chapter, but also the music arising from their interconnections, even their counterpoints. The following is a brief introduction to the chapters that does not do them full justice.

Chapter 2 gives voice to Fileberto Reynaldo Lopez, a member of the Pascua Yaqui tribe. Fileberto tells us about the "evaluation" to which he and the members of his linguistic group were subject as he grew up. Whether formal or not, evaluation is always about social relations. In his world, nothing is begun, not even evaluation, before everybody is present. This apparently simple statement testifies to a deeply rooted set of values related to a given cultural 
community characterized by a we-orientation rather than an I-orientation. These values are pre-evaluative in the sense that they exist in a given cultural space long before formal evaluation comes in. When such pre-evaluative values are articulated (which is perhaps better done by someone not taking Western, rational evaluation imagery for granted), evaluators are faced with the challenge to think more deeply about how they engage with such values in their own work.

In Chapter 3, Jaakko Kauko and Mika Pajunen examine the Western rational evaluation imaginary from the inside, so to speak. Their key concept is "the thickening modern," and they argue that, even in the face of postmodern ontological uncertainty in society, there is a tendency to epistemologically cling to rationalist epistemology. In my reading, the consequence is that important pre-evaluative values in evaluation and in other contemporary issues remain hidden behind the fog created by the thickening modern.

In Chapter 4, Estelle Raimondo discusses the internal and external forces that have made evaluation an important if not dominant institutionalized practice in a large international organization, which has served as a beacon of international evaluation. She discusses whether it is possible to curb the evaluation wave and make more out of less evaluation while at the same time cultivating the power of evaluation to renew the organization.

In Chapter 5, Sotiria Grek studies the role of international organizations in the production of global metrics. Based on perspectives from political sociology, science, and technology studies, as well as studies of quantification, she shows how metrics play an increasingly important role in transnational governance. Given how an understanding of the institutionalization and legitimation of evaluation hinges on particular problematizations, she argues that certain forms of ignorance are also produced and should be part of the broader understanding of global metrics.

In Chapter 6, Lehn Benjamin looks at the role of conventional evaluation terms such as "programs" and "recipients," which restrict the understanding of social change in nonprofit and voluntary organizations. Alternatively, by understanding the many hats that people wear and their active roles, evaluators might help stakeholders not simply unpack the assumptions of their program but also consider how the characteristics or features of the organization including its structure, design, and the role of beneficiaries - affect its overall impact on beneficiaries for better or worse. In this transformation, a reflection on evaluation terminology itself is crucial. 
In a way that resonates with Benjamin's thoughts about evaluation forms and shapes expectations to people and their roles, Maria Ørskov Akselvoll and Peter Dahler-Larsen distinguish between "evaluation people" and "real people" in Chapter 7. While "evaluation people" are skilled in dealing with evaluative data, "real people" have limited resources, data skills, and time. The analytical distinction makes it possible to trace how the evaluation society also manifests itself in terms of unequal social relations; in this case, in the specific context of home-school cooperation, as shown in Akselvoll's study of class differences in parental involvement in Danish schools (Akselvoll, 2016).

The following three chapters present visions about how evaluation can be collaborative and participatory.

In Chapter 8, Jill Anne Chouinard maps the ecology of collaborative practices in evaluation. She argues that a focus on methodology all too often distracts from deeper epistemological issues. She shows how epistemology is anchored in institutional, political, and cultural practices. The future of collaborative approaches hinges on its engagement with these issues, not only on methods.

In Chapter 9, Emily St. Denny carries this torch further, this time specifically into feminist evaluation. After discussion of the central role of social justice, the chapter highlights the lack of consensus among feminist scholars about how best to represent women's interests (without essentializing a particular view of women) and explores the implications for carrying out policy evaluations in line with feminist research principles.

In Chapter 10, Ismael Rafols and Andy Stirling consider the existing practices in research evaluation. The use of indicators is generally associated with reduced perspectival diversity - effectively closing down debate. However, indicators can also be used to help support more plural evaluation and foster more productive, critical debate. This can be done by, first, broadening the range of "inputs" taken into account; and second, opening up the "outputs" in the sense of developing methodologies for indicator-based analyses to help in considering plural perspectives. In practice, this means a move toward the more situated and participatory use of quantitative evidence in evaluation, a shift from universal indicators to contextualized indicating. Although their chapter remains thematically confined to research evaluation, their recommendations apply to a broad range of domains in which evaluation is carried out.

In Chapter 11, Bénédicte Vidaillet offers a different and radical critique of the evaluation wave (as it manifests in assessments and evaluations at work). She 
argues that "evaluation victims" are also often "accomplices." Drawing on a psychoanalytic perspective from Lacan, she shows how, even if the detrimental effects of evaluation are well known, we all share a desire to be evaluated. She argues that if these motives are better known, evaluation will no longer be seen as a cure for lack of motivation at work, unhealthy relations with colleagues, or our insatiable appetite for recognition.

In Chapter 12, Felicitas Hesselmann and Cornelia Schendzielorz discuss the rhetorical power of evaluations. They analyze the link between values and measurements, and they argue that this link is sometimes reconstructed rhetorically as evaluation travels from one context to another. They point to the roles of power and rhetoric in defining and redefining the meaning of evaluative data across time and space, using a discussion of how to measure the "societal impact" of academic research as an illustrative example.

In my reading, their perspective suggests that evaluation can have major implications that reach far beyond the intentions invested in it during its "original production" (known as unintended effects or constitutive consequences), but it also allows an opening in analyses of evaluation, since its meaning is constantly up to a contextualized form of renegotiation and reconstruction.

In other words, Chapters 11 and 12 suggest that the responsibility for evaluation and its use is widely diffused. The evaluation society and our implication in it are not two separate phenomena. As we "use" and "recycle" evaluation in different contexts, we are at the same time creating and recreating the evaluation society in its specific forms.

\section{References}

Akselvoll, M. Ø. (2016). Folkeskole, forceldre, forskelle - Skole-hjem-samarbejde og forceldreinvolvering i et klasseperspektiv (PhD thesis). Department of Psychology and Educational Studies, Roskilde University.

Becker, Howard S. (2017). Evidence. Chicago, IL: University of Chicago Press.

Behn, R. (2003). Why Measure Performance? Different Purposes Require Different Measures. Public Administration Review, 63 (5), pp. 585-606.

Bruno, I., Didier, E., \& Vitale, T. (2014). Statactivism: Forms of Action between Disclosure and Affirmation. Partecipazione e Conflitto - Participation and Conflict, 7 (2), pp. 198-220.

Butler, J. (2010). Performative Agency. Journal of Cultural Economy, 3 (2), pp. 147-61.

Chelimsky, E. (2006). The Purposes of Evaluation in a Democratic Society. In Shaw, I., Greene, J. C., \& Mark M. M. (eds). The Sage Handbook of Evaluation. London: Sage. 
Dahler-Larsen, P. (2012). The Evaluation Society. Stanford, CA: Stanford University Press.

Dahler-Larsen, P. (2013). Constitutive Effects of Performance Indicators: Getting Beyond Unintended Consequences. Public Management Review, 16 (7), pp. 969-86.

Dahler-Larsen, P. (forthcoming). Your Brother's Gatekeeper. In Forsberg, E., Geschwind, L., Levander, S., \& Wermke, W. (eds). Scientific Communication and Gatekeeping in Academia in the 21st Century. Basingstoke: Palgrave.

Dewey, J. (1946). The Public and Its Problems. Chicago, IL: Gateway Books.

Espeland, W., \& Sauder, M. (2007). Rankings and Reactivity: How Public Measures Recreate Social Worlds. American Journal of Sociology, 113 (1), pp. 1-40.

Esposito, E., \& Stark, D. (2019). What's Observed in a Rating? Rankings as Orientation in the Face of Uncertainty, Theory, Culture and Society, 36 (4), pp. 3-26.

Feyerabend, P. (2010). Against Method (4th edn). New York: Verso.

Grek, S. (2009). Governing by Numbers: The PISA "Effect" in Europe. Journal of Education Policy, 24 (1), pp. 23-37.

Grek, S., Lawn, M., Lingard, B., Ozga, J., Rinne, R., Segerholm, C., \& Simola, H. (2009). National Policy Brokering and the Construction of the European Education Space in England, Sweden, Finland and Scotland. Comparative Education, 45 (1), pp. 5-21.

Kerpershoek, E., Groenleer, M., \& de Bruijn, H. (2016). Unintended Responses to Performance Management in Dutch Hospital Care: Bringing Together the Managerial and Professional Perspectives. Public Management Review, 18 (3), pp. 417-36.

Kirkhart, K. E. (2000). Reconceptualizing Evaluation Use: An Integrated Theory of Influence. In Caracelli, V. J., \& Preskill, H. (eds). New Directions for Evaluation. San Francisco, CA: Jossey-Bass.

Klouzal, L., Shayne, J. D., \& Foran, J. (2003). Visions 4. In Bhavnani, K.-K., Foran, J., \& Kurian, A. P. (eds). Feminist Futures: Re-Imagining Woman, Culture and Development. London: Zed Books.

Law, J. (2004). After Method: Mess in Social Science Research. New York: Routledge.

Mark, M., \& Henry, G. (2003). The Mechanisms and Outcomes of Evaluation Influence. Evaluation, 10 (1), pp. 35-57.

Mathison, S. (1991). Role Conflicts for Internal Evaluators. Evaluation and Program Planning, 14 (3), pp. 173-9.

Morin, E. (1990). Metoden: Kendskaben til Kundskaben, en Erkendelsens Antropologi (translation by Jørgen Jørgensen). Åbyhøj: Ask.

Podems, D. (2018). Being an Evaluator: Your Practical Guide to Evaluation. New York: Guilford Press.

Power, M. (1997). The Audit Society. Oxford: Oxford University Press.

Raimondo, E. (2018). The Power and Dysfunctions of Evaluation Systems in International Organizations. Evaluation, 24 (1), pp. 26-41.

Rossi, P. H., \& Freeman, H. E. (1985). Evaluation: A Systematic Approach. Beverly Hills, CA: Sage.

Schwandt, T. A. (2002). Evaluation Practice Reconsidered. New York: Peter Lang.

Scriven, M. (1991). Evaluation Thesaurus (4th edn). London: Sage.

Shadish, W. R., Cook, T. D., \& Leviton, L. (1991). Foundations of Program Evaluation. Thousand Oaks, CA: Sage.

Wynne, B. (1996). May the Sheep Safely Graze? A Reflexive View of the Expert-Lay Knowledge Divide. In Lash, B., Szerszynski, B., \& Wynne, B. (eds). Risk, Environment and Modernity: Towards a New Ecology. London: Sage. 
Peter Dahler-Larsen - 9781839101083 Downloaded from PubFactory at 04/26/2023 01: $00: 53 \mathrm{PM}$ via free access 